\title{
Drug-Antibody-Platelet Interaction in Quinine- and Quinidine-induced Thrombocytopenia
}

\author{
Douglas J. Christie and Richard H. Aster, Blood Center of Southeastern \\ Wisconsin, Milwaukee, Wisconsin 53233; Departments of Medicine and \\ Pathology, Medical College of Wisconsin, Milwaukee, Wisconsin 53226
}

A в S T R A C T Binding of quinine- and quinidine-dependent antibodies to platelets was studied using an electroimmunoassay to measure platelet-bound IgG. Antibodies from four patients with drug-induced thrombocytopenia differed significantly in their interaction with platelets: association constants for binding to platelets at high drug concentrations ranged from 0.29 to $2.6 \times 10^{7} \mathrm{M}^{-1}$, the maximum number of antibody molecules bound ranged from 36,000 to $161,000 /$ platelet, the amount of drug necessary to achieve half-maximum binding of antibodies to platelets ranged from 2 to $60 \mu \mathrm{M}$, and only one of the antibodies cross-reacted with the stereoisomer of the drug to which the patient was sensitized. Binding of the antibodies to platelets was enhanced at the highest achievable molar ratio of drug:antibody, 10,000:1, rather than being inhibited, as would be expected in a conventional, hapten-dependent reaction. The drugantibody-platelet reaction was unaffected by Factor VIII/von Willebrand protein, nonspecifically aggregated IgG, or heat-labile complement components. After pretreatment with tritiated quinine, platelets retained several hundred thousand molecules of drug each, but failed to bind detectable amounts of antibody. However, platelets treated simultaneously with quinine-dependent antibody and tritiated quinine retained significantly more drug after repeated washes than platelets treated with drug and normal serum.

These findings support the proposition that in quinine- and quinidine-induced thrombocytopenia, drug and antibody combine first in the soluble phase to form a complex, which then binds with high affinity to a receptor on the platelet surface (innocent bystander reaction), and demonstrate that these antibodies are

A preliminary report was presented at the VIIIth International Congress on Thrombosis and Haemostasis, Toronto, Canada, 1981. Thromb. Haemostasis. 46: 296.

Received for publication 13 January 1982 and in revised form 30 June 1982. heterogeneous in respect to the amount of drug required to promote their binding to platelets, the number of platelet receptors they recognize, and their binding affinities.

\section{INTRODUCTION}

More than 50 different medications are capable of triggering immunologic destruction of platelets in man (1). Of these various medications the stereoisomers quinine and quinidine appear to provoke this disorder most commonly. Antibodies associated with this phenomenon generally bind to platelets only in the presence of drug, but the molecular basis of the drug-antibody-platelet interaction (DAP) ${ }^{1}$ has not been fully characterized. Two mechanisms have been suggested to explain the etiology of drug-induced immunologic thrombocytopenia. Ackroyd (2) proposed that drug, acting as a hapten, modifies some platelet constituent to produce an antigen that stimulates antibody production. Subsequent challenge of a sensitized individual by the same drug would lead to drug-coated platelets that bind antibody and are destroyed. An alternate hypothesis developed independently by Miescher and Miescher (3) and Shulman (4) is that the antigen is formed by drug modification of some body constituent unrelated to platelets and that rechallenge with drug induces antibodies that combine first with drug to form soluble immune complexes and then to platelets by a mechanism not yet understood. The latter hypothesis has been termed "innocent bystander" (5) because the platelet itself is not involved in formation of the primary antigen. Shulman $(4,6)$ provided experimental support for the latter proposal by showing that quin-

\footnotetext{
${ }^{1}$ Abbreviations used in this paper: DAP, drug-antibodyplatelet interaction or complex; ddAb, drug-dependent antibody; $\left[{ }^{3} \mathrm{H}\right] \mathrm{Qn}$, tritiated quinine; PAIgG, platelet-associated IgG; TX-100, Triton X-100; VIIIR:Ag, Factor VIII-related antigen; vWd, von Willebrand's disease.
} 
idine binds only weakly to the platelet surface and is therefore unlikely to form an antigenic hapten-carrier complex and that high concentrations of quinidine fail to inhibit the binding of antibody to platelets, as would be expected in a classic hapten-antibody reaction.

Recently, Hosseinzadeh et al. (7) provided new evidence to support Ackroyd's hypothesis (2) by showing that lymphocytes from patients who had experienced quinine- or quinidine-induced thrombocytopenia could be stimulated by platelets previously exposed to drug in the presence of plasma and then washed, but not by drug or platelets alone. They suggested that the stimulating antigen was formed by drug complexed to the platelet membrane with the aid of a plasma cofactor. Further complexity has been introduced by the finding of Pfueller et al. (8) that quinine- and quinidine-dependent antibodies fail to induce platelet immunoinjury in plasma lacking Factor VIII-related antigen (VIIIR:Ag), which suggests that the Factor VIII complex is involved in DAP formation.

Hundreds of different medications appear to be capable of inducing tissue injury by immunologic means (9-11) and it seems possible that better characterization of the mechanism(s) of drug-induced immunologic thrombocytopenia may provide clues to the pathogenesis of a broader spectrum of disease. We have therefore studied the interaction of platelet, drug, and drug-dependent antibody (ddAb), using tritiumlabeled drug and a direct method for the determination of platelet-associated IgG (PAIgG).

\section{METHODS}

Chemicals. Quinidine hydrochloride and bovine serum albumin (Fraction V) were from Sigma Chemical Co. (St. Louis, MO), and quinine hydrochloride was from Aldrich Chemical Co. (Milwaukee, WI). Sodium ${ }^{51} \mathrm{Cr}$ with specific activity of $200-500 \mathrm{Ci} / \mathrm{g}$ (for platelet labeling) was from Amersham-Searle Corp. (Arlington Heights, IL). DEAE-Sephadex A50 was from Pharmacia Fine Chemicals (Piscataway, NJ). Agarose (Standard Low-M r $_{\mathrm{r}}$, Triton X-100 (TX100), and Coomassie Blue R were from Bio-Rad Laboratories (Richmond, CA). Gel supports were made from Gel-Bond (Marine Colloids, Inc., Rockland, ME). Complete Counting Cocktail 3a20 was from Research Products International Corp. (Elk Grove, IL). All other chemicals were standard analytical grade reagents.

Patients. Four patients fulfilling the clinical and laboratory diagnostic criteria of drug-induced immunologic thrombocytopenia were studied (1). Each developed profound thrombocytopenia after courses of therapy ranging from 1 to $4 \mathrm{wk}$ and recovered within 3 to $7 \mathrm{~d}$ after the offending drug was discontinued. Two possessed quininedependent antibodies (I.L. and R.S.) and two quinidine-dependent antibodies (D.D. and M.S.). Each antibody was readily detectable by complement-mediated lysis of ${ }^{51} \mathrm{Cr}-$ tagged platelets (12) and indirect immunofluorescence using anti-IgG (13) and reacted with platelets only in the presence of drug.

Platelet preparation. Blood drawn from normal healthy volunteers and patients was anticoagulated with either EDTA or sodium citrate at final concentrations of 8 and 30 $\mathrm{mM}$, respectively. Platelet-rich plasma was prepared by differential centrifugation, as previously described (12). In some experiments, von Willebrand's disease (vWd) and normal platelets frozen in dimethylsulfoxide were used (14). Platelets were isolated from blood of a patient with the Bernard-Soulier syndrome (kindly supplied by Dr. Margaret Johnson, Wilmington, DE), as previously described $(15,16)$. Platelet concentration was determined by phase microscopy. Protein concentrations of platelets solubilized in TX-100 were determined by the method of Markwell et al. (17). Unless otherwise stated, experiments were performed with platelets pooled from at least three normal group $O$ donors (PAIgG levels $4.0 \pm 1.1 \mathrm{fg} /$ platelet) out of a group of seven individuals. EDTA was present at $7.6 \mathrm{mM}$ in all experiments.

Electroimmunoassay for PAIgG. Serum or plasma was incubated with 1.5-3.0 $\times 10^{8}$ buffer-washed or unwashed platelets in the presence of the appropriate drug or saline. In preliminary experiments it was determined that maximum binding of antibody to platelets occurred in $<20 \mathrm{~min}$ at $22^{\circ} \mathrm{C}$ with gentle agitation. It was also found that platelets washed several times in buffer bound $\sim 50-60 \%$ more ddAb than unwashed platelets. Except where otherwise noted, unwashed platelets were used in the experimental studies. After the incubation, platelets were washed twice at $22^{\circ} \mathrm{C}$ in EDTA, phosphate-buffered saline (EDTA-PBS) $(7.6 \mathrm{mM})$, pH 7.3, containing a concentration of drug equal to that used in the initial incubation, except where otherwise noted. Two washes were found to be sufficient to remove all loosely bound IgG and PAIgG values were unchanged by up to four additional washes. Except where otherwise indicated, two washes were used before determining all PAIgG values.

Determination of PAIgG was accomplished by an electroimmunoassay method described elsewhere by Kunicki and Aster (18). Platelets previously incubated with ddAb and then washed twice were solubilized by agitation in $0.5 \% \mathrm{TX}$ 100 in $0.1 \mathrm{M}$ sodium acetate, $\mathrm{pH} 5.0$, at $4^{\circ} \mathrm{C}$ for $30 \mathrm{~min}$. Solubilized samples of $10-45 \mu \mathrm{l}$ were loaded into wells of a $1 \%$ agarose gel containing a predetermined amount of carbamoylated rabbit IgG specific for the gamma chains of human IgG. Carbamoylation lowered the pI of the rabbit IgG from $\sim 7$ to 5 , preventing its migration during electrophoresis (19). Gels were electrophoresed at $2 \mathrm{~V} / \mathrm{cm}$ for 18 $\mathrm{h}$ at $15^{\circ} \mathrm{C}$ in $0.1 \mathrm{M}$ sodium acetate, $\mathrm{pH} 5.0$, washed in saline, dried, and stained with $0.5 \%$ (wt/vol) Coomassie Blue $\mathrm{R}$ in $45 \%$ ethanol/10\% acetic acid. Destaining was carried out in $45 \%$ ethanol/10\% acetic acid. The resulting peak heights of the immunoprecipitates were directly proportional to the total amount of PAIgG present in each sample. A linear standard curve was obtained using known quantities of purified human IgG in $10 \%$ (wt/vol) bovine serum albumin. PAIgG of platelets incubated in seven different normal plasma samples in the presence or absence of drug or in the four ddAb-containing plasmas in the absence of drug ranged from 10,000 to 20,000 molecules $(2.5-5.0 \mathrm{fg}) / \mathrm{platelet}$, within the normal range reported by Kunicki and Aster (18) and others $(20,21)$. The term "ddAb", as used in Figs. 1, 2, 3 and Table I refers to the net PAIgG determined by subtracting control PAIgG (measured in the absence of drug) from total PAIgG (measured in the presence of drug). The term "bound IgG", as used in Figs. 4 and 5, refers to total PAIgG.

Measurement of VIIIR:Ag. VIIIR:Ag in platelets and plasma was determined with a modification of the quantitative immunodiff usion assay reported by Glode et al. (22), in which plasma and platelets (solubilized in $0.1 \% \mathrm{TX}-100$ ) 
are electrophoresed into $0.9 \%$ agarose gels containing ${ }^{125} \mathrm{I}$ rabbit antihuman VIIIR:Ag antibody. The resulting rockets were detected by autoradiography.

Preparation of ddAb free of VIIIR:Ag. Plasma samples were made essentially free of VIIIR: $\mathrm{Ag}$ by a modification of the technique of Zimmerman et al. (23). Briefly, samples were treated with DEAE-Sephadex A50 beads in $0.005 \mathrm{M}$ $\mathrm{KH}_{2} \mathrm{PO}_{4}, 0.005 \mathrm{M} \mathrm{K}_{2} \mathrm{HPO}_{4}, \mathrm{pH}$ 8.0. Beads packed by centrifugation at $12,800 \mathrm{~g}$ for $2 \mathrm{~min}$ in an Eppendorf Micro Centrifuge (Brinkmann Instruments, Inc., Westbury, NY), after removal of buffer, were mixed with plasma containing $\mathrm{ddAb}$ at a ratio of $1 \mathrm{ml}$ beads (unpacked volume) to $0.5 \mathrm{ml}$ plasma and rotated gently for $15 \mathrm{~min}$ at ambient temperature. The mixture was centrifuged at $12,800 \mathrm{~g}$ for $2 \mathrm{~min}$. The supernatant contained levels of VIIIR:Ag ranging from 0.1 to $0.0001 \%$ (limit of detection) of that present in the starting plasma. Levels of IgA and IgM were $<20 \%$ of those in starting plasma, as measured by radial immunodiff usion (Helena Laboratories, Beaumont, TX), whereas IgG levels were not significantly reduced.

Preparation and use of tritiated quinine $\left(\left[{ }^{3} \mathrm{H}\right] \mathrm{Qn}\right)$. Quinine hydrochloride was submitted to New England Nuclear (Boston, MA) for catalytic hydrogen exchange with carrierfree tritium oxide. The tritiated product was purified by preparative thin-layer chromatography on silica gel $60 \mathrm{~F}_{254} \mathrm{~S}$ (MCB Reagents, E. Merck, Darmstadt, Cincinnati, OH) with a solvent system of chloroform:triethylamine:ethanol (90:5:5) (24). The tritiated drug, localized by fluorescence, was eluted from the gel in absolute ethanol, evaporated to dryness using a Buchi Rotavapor-R (Brinkmann Instruments) and reconstituted in distilled water. Material prepared in this way was stored at $4^{\circ} \mathrm{C}$ for up to several weeks. Periodic analysis for racemization by analytical thin-layer chromatography always showed tritium comigrating only with nonradiolabeled quinine and distinct from quinidine. The solvent system used separates all of the common sterioisomers of quinine (24).

The molar absorptivity of quinine hydrochloride was measured in water and found to be $4,700 \mathrm{M}^{-1} \mathrm{~cm}^{-1}$ at a wave- length of $330 \mathrm{~nm}$. Concentrations of $\left[{ }^{3} \mathrm{H}\right] \mathrm{Qn}$ (optical spectrum identical to quinine hydrochloride) were determined spectrophotometrically using this value. The specific activity of purified $\left[{ }^{3} \mathrm{H}\right] \mathrm{Qn}$ was $10 \mathrm{mCi} / \mathrm{mmol}$.

Tritium bound to platelets was assayed after solubilization in 3a20:TX-100 (2:1) in an Isocap/300 6872 liquid scintillation system (Searle Radiographics, Des Plaines, IL).

\section{RESULTS}

Binding of antibody to platelets as a function of drug concentration. Platelets were incubated with $\mathrm{ddAb}$ in the presence of quinine or quinidine to determine the relationship between drug concentration and antibody binding. As shown in Fig. 1 and Table I, the four antibodies required different amounts of drug to promote attachment of IgG to platelets. Under conditions described in the legend to Fig. 1, the amount of drug required to produce one-half maximum ddAb binding per platelet ranged from 2 (M.S. plus quinidine) to $60 \mu \mathrm{M}$ (I.L. plus quinine).

Maximum number of platelet receptors for drugdependent antibody. Using drug concentrations determined to be sufficient for maximum antibody binding (Fig. 1), we incubated platelets with increasing amounts of plasma containing ddAb to determine the maximum amount of antibody each was capable of attaching to platelets. As shown in Fig. 2 and Table $\mathrm{I}$, the number of antibody binding sites measured in this way ranged from 36,000 (M.S. plus quinidine) to $161,000 /$ platelet (I.L. plus quinine). To determine whether variability in the amount of IgG bound to

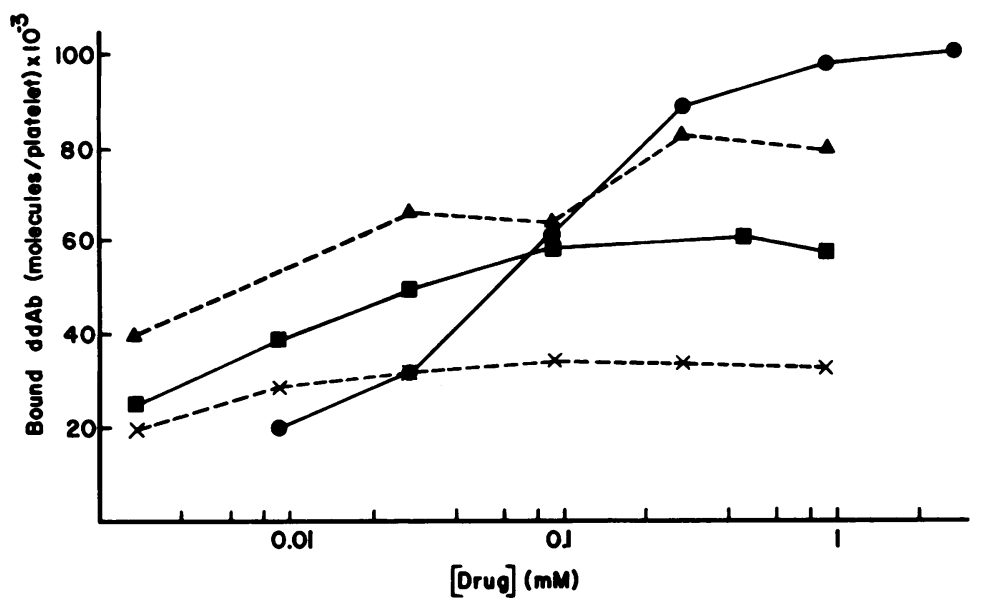

Figure 1 Binding of ddAb to platelets at various drug concentrations. Plasma from patients I.L., $1.0 \mathrm{ml}(\Theta)$; R.S., $1.0 \mathrm{ml}(\square)$; D.D., $1.0 \mathrm{ml}(\Delta)$; and M.S., $2.0 \mathrm{ml}(\times)$ were incubated with $3 \times 10^{8}$ platelets in the presence of quinine $(-)$ or quinidine (- - ). After incubation for $20 \mathrm{~min}$ at $22^{\circ} \mathrm{C}$, the platelets were washed twice in EDTA-PBS containing $0.5 \mathrm{mM}$ drug. Platelet-bound ddAb was calculated as described in Methods. Data points are the average of duplicate determinations for a single experiment. Results shown are representative of two separate experiments performed with each antibody, each of which yielded essentially identical results. 
TABLE I

Characteristics of Antibodies from Four Patients with Drug-induced Thrombocytopenia

\begin{tabular}{|c|c|c|c|c|c|}
\hline Patient & Drug & Maximum ddA $b^{\circ}$ & [drug]t & $\begin{array}{c}\text { [ddAb] } \\
\text { in patient's plasma } \S\end{array}$ & $K . \$$ \\
\hline & & molecules/platelet & $\mu M$ & $n M$ & $M^{-1}$ \\
\hline I.L. & Quinine & $161,000 \pm 8,000$ & 60 & $180 \pm 10$ & $7.9 \pm 0.5 \times 10^{6}$ \\
\hline R.S. & Quinine & $50,000 \pm 7,000$ & 4 & $170 \pm 20$ & $2.6 \pm 0.5 \times 10^{7}$ \\
\hline D.D. & Quinidine & $77,000 \pm 14,000$ & 6 & $150 \pm 10$ & $2.2 \pm 0.2 \times 10^{7}$ \\
\hline M.S. & Quinidine & $36,000 \pm 6,000$ & 2 & $150 \pm 40$ & $2.9 \pm 0.6 \times 10^{6}$ \\
\hline
\end{tabular}

- Mean \pm SD for at least three experiments performed in duplicate.

$\downarrow$ Drug concentrations producing one-half maximum ddAb binding per platelet.

$\$$ Average \pm one-half the range for two separate experiments.

platelets by the different antibodies was due to the presence in one or more samples of $\operatorname{IgA}$ or IgM ddAb capable of competing with IgG ddAb for the same receptor, the binding studies were repeated with ddAb depleted of IgA and IgM (see Methods). The four antibodies so treated displayed essentially the same pat-

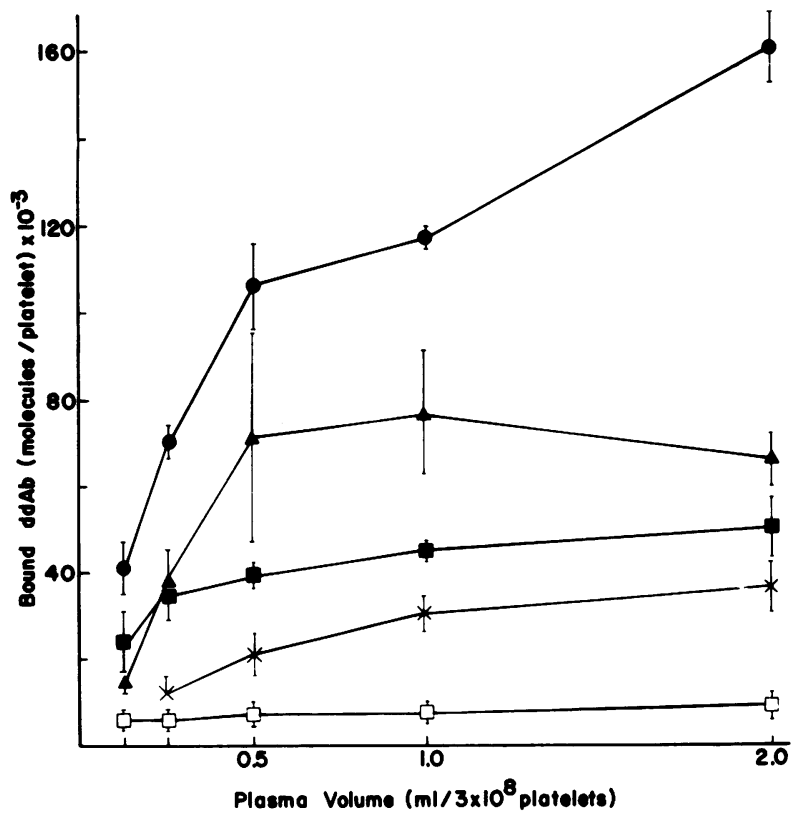

Figure 2 Maximum binding of ddAb to platelets. Different volumes of plasma from patients, I.L. (O), R.S. (口), D.D. $(\Delta)$, and M.S. $(X)$, were incubated with $3 \times 10^{8}$ platelets and either quinine $(0.9 \mathrm{mM}$ with I.L. and $0.45 \mathrm{mM}$ with R.S.) or quinidine $(0.9 \mathrm{mM}$ with D.D. and $0.45 \mathrm{mM}$ with M.S.) and then washed as in Fig. 1. Platelet-bound ddAb was calculated as described in Methods. A typical example of PAIgG values obtained in the absence of drug is shown for R.S (ם). Data points and error bars are the mean \pm SD for at least three separate experiments performed in duplicate. No further increase in bound ddAb was observed when $4.0-\mathrm{ml}$ vol of plasma were used (not shown). tern of drug-dependent IgG binding shown in Fig. 2 for unfractionated plasma. Further, IgM and IgA could not be detected by immunofluorescence testing of ddAb-coated platelets, in contrast to strong positive reactions obtained with fluorescent anti-IgG.

Drug-dependent antibody binding was unaffected by chelation of divalent cations with EDTA, substitution of serum for plasma, heating at $56^{\circ} \mathrm{C}$ for $30 \mathrm{~min}$ to inactivate heat-labile complement components or by removal of IgG aggregates by ultracentrifugation for $60 \mathrm{~min}$ at $73,000 \mathrm{~g} \mathrm{(25)}$. Platelets from seven normal donors studied separately did not differ significantly from each other in their reactions with the four antibodies studied.

Effect of VIIIR:Ag on ddAb binding. Because of a recent report by Pfueller et al. (8) that VIIIR:Ag is required for induction of aggregation, serotonin release, and platelet factor 3 activation by quinine- and quinidine-dependent antibodies, studies were performed to determine whether VIIIR:Ag is necessary for ddAb binding to platelets. EDTA-plasma containing each of the four antibodies was made VIIIR:Agfree as described in Methods. The final preparation contained $\sim 80 \%$ of the starting quantity of ddAb, as determined by platelet cytotoxicity, but $<0.001 \%$ of the initial quantity of VIIIR:Ag, as determined by radioimmunoassay (22). With this preparation, ddAb binding by the four samples was indistinguishable from that shown in Fig. 2 for the untreated plasma. Similar results were obtained with platelets from two patients with severe Type I vWd (VIIIR:Ag levels $<0.1 \%$ of normal).

Determination of ddAb concentrations and association constants for DAP formation. The approximate concentration of ddAb in each patient's plasma was determined by incubating a fixed amount of plasma with increasing numbers of platelets in the presence of excess drug to determine the maximum amount of ddAb that could be bound to platelets per 
milliliter of plasma as shown for antibody R.S. in Fig. 3. Little difference in ddAb concentration was found in the plasma of the four patients studied (Table I).

The $K_{\mathrm{a}}$ for DAP formation was calculated from a standard equilibrium expression for antibody binding to a cell receptor, on the assumption that the equilibrium between free antibody and antibody bound to platelets is not significantly influenced by excess drug. This assumption is reasonable because a study by Shulman (6) and our own findings described below indicate that excess drug promotes, rather than inhibits, antibody binding. On the assumption that the stoichiometry of binding between antibody and platelet receptor is $1: 1$, at the point where half of the antibody is bound (see arrow, Fig. 3) the reciprocal of the molar concentration of free platelet receptor sites provides an estimate of the $K_{a}$ for DAP formation. The four antibodies studied differed significantly in their $K_{\mathrm{a}}$ values (Table I): the $K_{\mathrm{a}}$ for R.S. and D.D. were an order of magnitude greater than the Ka for M.S., and approximately three times higher than the $K_{\mathrm{a}}$ for I.L. The high end of our $K_{\mathrm{a}}$ range of $0.29-2.6 \times 10^{7} \mathrm{M}^{-1}$ is close to the value of $4 \times 10^{7} \mathrm{M}^{-1}$ estimated by Shulman (4) for a single quinidine-dependent antibody using a different experimental approach.

Cross-reactivity with quinine and quinidine. The quinine-dependent antibody R.S. differed from the others studied in that quinidine also promoted binding of IgG to platelets and release of ${ }^{51} \mathrm{Cr}$ from tagged platelets. No IgG binding or ${ }^{51} \mathrm{Cr}$ release was observed with the other three antibodies using the stereoisomer of the compound to which the patients were sensitized.

Effect of washing in the presence and absence of drug on the binding of antibody to platelets. Plate- lets were incubated with either quinine or quinidine in the presence of quinine- and quinidine-dependent antibodies, respectively, and then washed in either EDTA-PBS or EDTA-PBS containing the same drug at a concentration of $1 \mathrm{mM}$, a 3,000-fold molar excess of drug:antibody. As shown in Fig. 4 for antibody I.L., significantly more IgG was retained by platelets when they were washed in the presence of drug than in its absence. After four washes, 72,800 $\pm 9,900$ molecules of IgG were bound per platelet when drug was included in wash solutions, but only $28,900 \pm 7,400$ when drug was absent $(P<0.001)$. It is apparent that excess drug, rather than promoting dissociation of antibody from platelets as would be expected in a classic haptenantibody reaction (26), increases the affinity of antibody for its receptor. Association of normal IgG with platelets was not affected by the presence or absence of drug in wash solutions (not shown).

Binding of quinine to platelets. To determine whether platelets pretreated with drug retain significant quantities of drug after washing, $3 \times 10^{8}$ unwashed platelets were incubated with $0.4 \mathrm{mM}\left[{ }^{3} \mathrm{H}\right] \mathrm{Qn}$ in $1.0 \mathrm{ml}$ fresh normal plasma for $20 \mathrm{~min}$ at $37^{\circ} \mathrm{C}$ under the same conditions as shown in Fig. 5. After two washes, the platelet mixture retained $1.8 \pm 0.2$ $\times 10^{14}($ mean $\pm \mathrm{SD}, n=3)$ drug molecules. This is $>300$ times the amount expected on the basis of simple dilution $\left(5.4 \times 10^{11}\right)$ calculated by using $3 \mu \mathrm{l}$ as the total volume of the platelet pellet and $2.0 \mathrm{ml}$ as the volume per wash and represents a retention of $5.9 \pm 0.6 \times 10^{5}$ drug molecules by each platelet. When platelets were incubated with $0.4 \mathrm{mM}\left[{ }^{3} \mathrm{H}\right] \mathrm{Qn}$ in the absence of plasma, $4.9 \pm 0.3 \times 10^{5}$ drug molecules were bound per platelet.

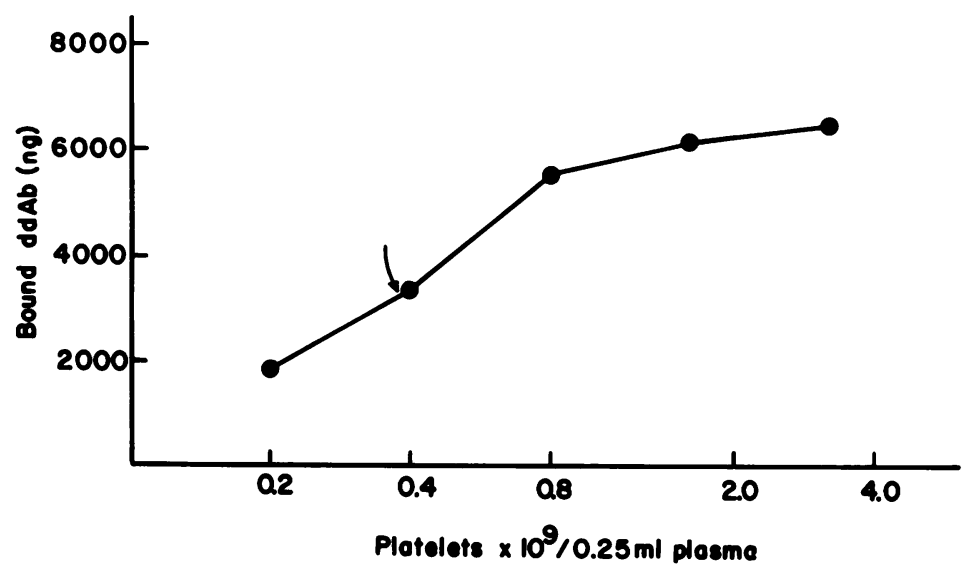

Figure 3 Determination of total ddAb. Increasing numbers of platelets were incubated with $0.25 \mathrm{ml}$ of plasma from R.S. in $0.45 \mathrm{mM}$ quinine, then washed in EDTA-PBS containing 0.45 $\mathrm{mM}$ quinine. Bound ddAb was determined as described in Methods. Results shown are the average of two experiments. The arrow indicates the point of half-saturation used to determine the $K_{\mathrm{a}}$ for complex formation of drug, antibody, and platelet receptor site (see text). 


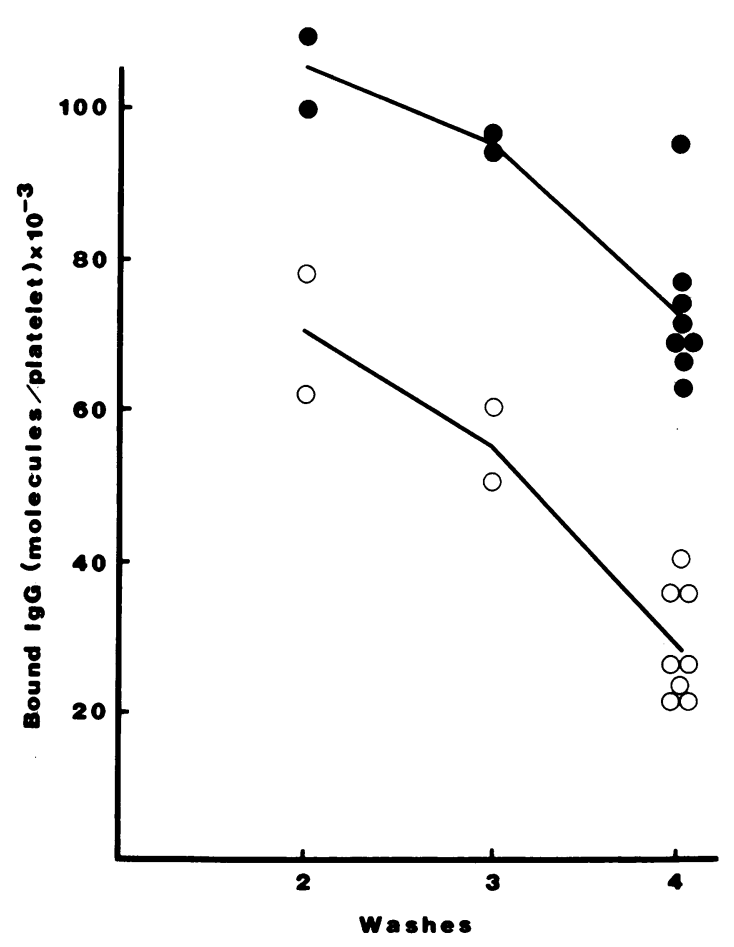

Figure 4 Effect of washing platelets in the presence and absence of drug on antibody binding. Plasma aliquots of 0.5 $\mathrm{ml}$ from patient I.L., containing a quinine-dependent antibody, were incubated with $1.5 \times 10^{8}$ platelets and $0.9 \mathrm{mM}$ quinine for $20 \mathrm{~min}$ at $22^{\circ} \mathrm{C}$. Samples were then washed two, three, or four times in either EDTA-PBS containing $1.0 \mathrm{mM}$ quinine (O) or in EDTA-PBS alone (O). Data shown are from two separate experiments where the lines connect the averages (two and three washes) and means (four washes) of the various sets of points for each wash. Similar results were obtained with antibodies from R.S. and M.S.

Incubation of antibody with platelets pretreated with drug. Hosseinzadeh et al. (7) have reported that platelets preincubated with quinine and quinidine in the presence of plasma and then washed are capable of inducing proliferation of lymphocytes from persons with quinine- and quinidine-induced thrombocytopenia. The following studies were performed to determine whether platelets pretreated with drugs are capable of binding ddAb. Platelets were pretreated with saline or quinine at various concentrations in the presence and absence of autologous plasma. The drugand saline-treated platelets were then washed three times in EDTA-PBS and tested for their ability to bind ddAb. As shown in Fig. 5, platelets preincubated with quinine in plasma failed to bind ddAb unless additional soluble drug was added. The same results (not shown) were obtained when autologous plasma was omitted or when only two washes rather than three were performed after the primary incubation. Results similar to those shown in Fig. 5 for I.L. were also obtained with plasma from R.S. Thus, platelets coated in plasma with several hundred thousand quinine molecules each (see above) by preincubation with the drug do not express receptors suitable for the attachment of ddAb unless additional drug is added.

Antibody-dependent binding of quinine to platelets. When antibody R.S. was incubated with platelets in the presence of $90 \mu \mathrm{M}\left[{ }^{3} \mathrm{H}\right] \mathrm{Qn}$ and the antibodycoated platelets were then washed six times with buffer, significantly more quinine was retained by the platelets than in controls using normal serum (Fig. 6). Because the six washes were performed in the absence of added drug, we can estimate from Fig. 4 that at least $75 \%$ of the platelet-bound ddAb was removed. On this assumption, the final estimated molar ratios of platelet-bound drug:antibody would be $8: 1$ and 17:1, respectively, for $1 \times 10^{9}$ and $3 \times 10^{8}$ platelets at a serum volume of $1.6 \mathrm{ml}$. Binding of more drug per cell with $3 \times 10^{8}$ than with $1 \times 10^{9}$ platelets presumably reflects the fact that antibody was no longer in excess with the larger number of platelets. Nonspecific trapping of quinine by aggregates of platelets is an unlikely explanation for the greater binding of tritium in the presence than in the absence of antibody because detectable clumping of the resuspended platelets did not occur and the same degree of drug retention was

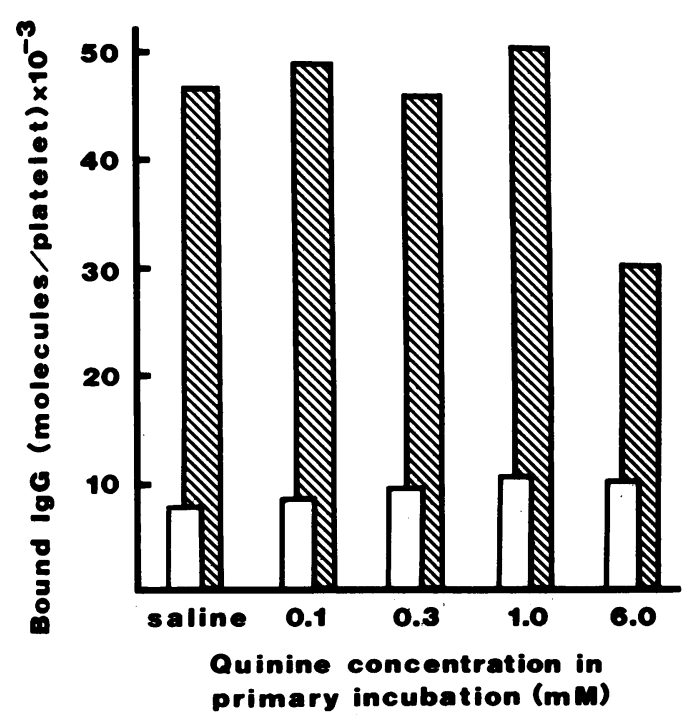

FIGURE 5 Binding of antibody to platelets pretreated with drug. $3 \times 10^{8}$ unwashed normal platelets in $0.45 \mathrm{ml}$ of autologous plasma were preincubated with varying amounts of quinine, as indicated along the abscissa, for $20 \mathrm{~min}$ at $37^{\circ} \mathrm{C}$ with stirring. Platelets were then washed three times in EDTA-PBS and incubated with $0.5 \mathrm{ml}$ of plasma from I.L. either in the presence (hatched bars) or absence (open bars) of $0.45 \mathrm{mM}$ quinine as described in Fig. 1. All samples were then washed twice in EDTA-PBS. Data shown are representative of three experiments. 


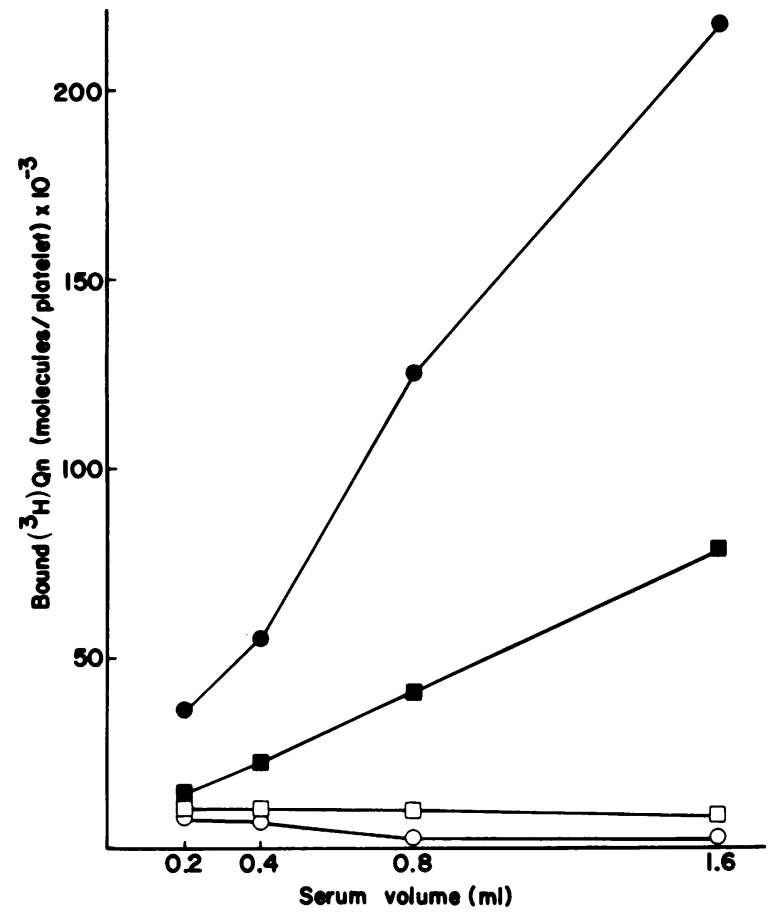

Figure 6 Binding of $\left[{ }^{3} \mathrm{H}\right] \mathrm{Qn}$ to platelets by a quinine-dependent antibody. Different amounts of antiserum from R.S. (closed symbols) or normal serum (open symbols) were incubated with either $3 \times 10^{8}$ platelets (circles) or $1 \times 10^{9}$ platelets (squares) and $90 \mu \mathrm{M}\left[{ }^{3} \mathrm{H}\right] \mathrm{Qn}$ for $20 \mathrm{~min}$ at $22^{\circ} \mathrm{C}$. Samples were then washed six times in EDTA-PBS and their content of $\left[{ }^{3} \mathrm{H}\right] \mathrm{Q}$ determined by liquid scintillation counting. Results are representative of two different experiments, each of which yielded essentially identical results.

observed with different quantities of platelets $(6.5$ $\times 10^{13}$ and $7.0 \times 10^{13}$ drug molecules for $3 \times 10^{8}$ and $1 \times 10^{9}$ platelets, respectively). The residual tritium was not due to precipitation of the drug by a serum component, since no radioactivity was detected in control tubes lacking platelets. Nor could it be explained by nonspecific adsorption to membranes damaged by ddAb, since $\left[{ }^{3} \mathrm{H}\right] \mathrm{Qn}$ did not bind specifically to platelets incubated with the quinidine-dependent antibody (D.D.) in the presence of the latter drug and then washed six times. Thus, platelet-bound ddAb appears to promote specific binding of drug to platelets and to inhibit its removal by washing.

Binding of ddAb to platelets from a patient with Bernard-Soulier syndrome. Washed platelets from a patient with Bernard-Soulier syndrome and a normal subject were incubated in plasma from R.S. and D.D. in the presence or absence of quinine and quinidine, respectively, under conditions that promote maximum antibody binding. After washing, the Bernard-Soulier platelets bound 29,000 (R.S.) and 70,000 (D.D.) dd Ab molecules each, while normal platelets bound 78,000
(R.S.) and 139,000 (D.D.) ddAb molecules each. Because the Bernard-Soulier platelets were much larger than normal, ddAb binding was calculated as a function of total platelet protein. The Bernard-Soulier platelets bound 470 (R.S.) and 1,140 (D.D.) ddAb molecules/ $\mu \mathrm{g}$ of platelet protein, whereas the normal platelets bound 3,540 (R.S.) and 6,290 (D.D.) ddAb molecules/ $\mu \mathrm{g}$ of platelet protein.

\section{DISCUSSION}

Heterogeneity of quinine- and quinidine-dependent antibodies. These studies demonstrate that quinine- and quinidine-induced antibodies are heterogeneous with respect to the concentration of drug required to promote their binding to platelets, their affinity for platelets in the presence of excess drug, the number of platelet receptors to which they are capable of binding, and their ability to cross-react with the stereoisomer of the drug that provoked sensitization. Each of the antibodies we studied appeared to be exclusively IgG. Others have found that drug-induced antibodies are occasionally $\operatorname{IgM}(4,27)$.

Few immunochemical studies of this class of antibodies have been performed. In studies conducted more than 20 years ago Shulman (6) detected binding of a quinidine-induced antibody to platelets at a drug concentration $<10^{-6} \mathrm{M}$ and showed that binding was maximum at $\sim 10^{-3} \mathrm{M}$. In a recent study of five quinidine-induced antibodies utilizing ${ }^{125}$ I-labeled staphylococcal protein A for antibody detection, Kekomaki et al. (28) found that antibody binding occurred at 2 $\times 10^{-6} \mathrm{M}$ quinidine and was maximum at $\sim 3 \times 10^{-4}$ M. Kelton et al. (20) studied five quinine- and quinidine-dependent antibodies using an antiglobulin consumption technique and found that one of these bound to platelets at a drug concentration of $2.7 \times 10^{-5} \mathrm{M}$, but that four others required drug concentrations at least 10 times higher. Each of the four ddAb we studied was capable of binding to platelets at concentrations of drug $<4 \times 10^{-6} \mathrm{M}$ (Fig. 1), a level achievable in circulating plasma following ingestion of these drugs in pharmacologic doses (29-31).

The only previous measurement of the binding affinity of ddAb to platelets appears to be that of Shulman (4), who found that the $K_{\mathrm{a}}$ for platelet binding of a quinidine-dependent antibody at high drug concentration was $\sim 4 \times 10^{7} \mathrm{M}^{-1}$, which is close to the range observed with our four antibodies $\left(2.9 \times 10^{6}\right.$ to $\left.2.6 \times 10^{7}\right)$. These values are, of course, only approximations in view of the polyclonal character of the antibodies studied and the requirement of the assay system for two washes before determination of PAIgG. More precise determination of the $K_{\mathrm{a}}$ values should be possible using purified radioactively labeled antibody. 
The variability in the number of platelet receptors for ddAb, ranging from 36,000 (M.S.) to 161,000 (I.L.)/platelet, was unexpected in the light of our previous finding that the primary receptor for quinineand quinidine-induced antibodies appears to be situated on glycoprotein $\mathrm{Ib}$, which is not known to vary significantly in freshly isolated platelets of normal subjects (16). On the basis of total platelet protein, antibodies R.S. and D.D. bound only 13 and $18 \%$ as well, respectively, to Bernard-Soulier platelets as to normal platelets in the presence of drug. This is consistent with our previous finding that Bernard-Soulier platelets lack or have reduced levels of the receptor for quinine- and quinidine-dependent antibodies (16). In a recent report, Kelton et al. (20) found that three quinidine-dependent antibodies bound between 40 and $69 \mathrm{fg}$ of $\mathrm{IgG} /$ platelet at a quinidine concentration of $10^{-3} \mathrm{M}$, and that one quinine-dependent antibody induced binding of $15 \mathrm{fg}$ of $\mathrm{IgG} /$ platelet at $10^{-3} \mathrm{M}$ quinine. If one assumes a molecular weight for IgG of 150,000 and subtracts the maximum value of $10 \mathrm{fg}$ obtained by Kelton et al. (20) for normal PAIgG, this translates into a range of 20,000 to 236,000 ddAb binding sites/ platelet. Although it is not clear whether antibody was in excess in Kelton's study, this range for antibody binding is comparable to the one we observed $(36,000-$ 161,000 ) (Table I). Our studies of platelets from different normal donors showed that this variability is a property of the antibodies themselves and not the platelets. Low values of IgG attached to platelets by M.S. may well have been related to its relatively low $K_{\mathrm{a}}$. However, antibody I.L. bound more than twice as much IgG per platelet as R.S. and D.D., despite having a lower $K_{\mathrm{a}}$ than the latter two antibodies and approximately the same concentration. Thus, our findings suggest that these antibodies differ in their specificities for receptor(s) on the platelet surface. Hosseinzadeh et al. (32) also described differences in the binding of quinine- and quinidine-dependent antibodies to platelet membrane proteins isolated by gel electrophoresis in a recent preliminary report. The basis for this variability is a subject of current investigation.

One of our antibodies (R.S.) also bound to platelets in the presence of the stereoisomer (quinidine) to which the patient was originally sensitized (quinine). This cross-reactivity appeared to be a property of a single antibody, since all reactivity with quinidine could be adsorbed with platelets in the presence of quinine. Kelton et al. (20), studying eight quinine- and quinidine-dependent antibodies, found that one quinine-dependent antibody reacted equally well with quinidine, whereas in their study of five quinidineinduced antibodies Kekomaki et al. (28) failed to detect any cross-reactivity with quinine. Shulman found that $20 \%$ of an unspecified number of quinine- and quinidine-induced antibodies cross-reacted with the appropriate stereoisomer (33).

Role of the Factor VIII complex in binding of ddAb to platelets. As noted previously, Pfueller et al. (8), in studies of seven quinine- and quinidine-induced antibodies, found that antibody activity as measured by tests involving release of platelet factor 3 , induction of platelet aggregation, and serotonin release could not be detected with citrated platelet-rich plasma from patients with severe $v W d$. On this basis, they suggested that the Factor VIII complex, known to be lacking in plasma of patients with $\mathrm{vWd}$, is required for the interaction of ddAb with platelets. Our studies demonstrate that dd Ab binds normally to platelets from normal subjects and from patients with $\mathrm{vWd}$ at levels of VIIIR:Ag $<0.001 \%$ of normal and at undetectable levels of VIII coagulant activity. These findings, together with those of Pfueller et al. (8), suggest the interesting possibility that the Factor VIII complex or one of its constituent parts is required for the mediation of immunoinjury after antibody has been affixed to the platelet membrane but not for the binding of antibody to platelets per se. The additional finding by Pfueller et al. (8) that VIIIR:Ag is required for drug-treated platelets to induce proliferation of lymphocytes from patients with drug-induced thrombocytopenia is not necessarily in conflict with our observations, since drug loosely bound to platelets after the two washes used by Pfueller might have directly stimulated $\mathrm{T}$ lymphocytes in their preparation. Clearly, additional studies are needed to elucidate the possible role of VIIIR:Ag in quinine- and quinidine-induced thrombocytopenia.

Mechanism of ddAb-platelet binding. Shulman (6), in an elegant series of studies of the interaction of a quinidine-dependent antibody with platelets, and aided by a theoretical analysis involving methods of statistical mechanics (34), concluded that his data did not permit a distinction to be made between two alternative models for DAP formation: one in which quinidine attaches first to antibody and a second in which quinidine attaches first to platelets. His study was limited by the need to use quantitative complement fixation as an index of antibody levels. However, it was postulated on the basis of the relatively weak binding of quinidine alone to platelets and the failure of high concentrations of the drug to inhibit antibody binding that a drug-antibody complex was formed first and that this complex subsequently became bound to a platelet receptor (4). Our findings that concentrations of drug $\sim 10,000$ times greater than antibody on a molar basis promote, rather than inhibit, binding of $\operatorname{ddAb}$ to platelets (Fig. 1, Table I) and that reversal of $\mathrm{ddAb}$ binding by repeated washes is inhibited by 
excess drug (Fig. 4) support this viewpoint. The observation that platelets preincubated with drug at various concentrations and then washed fail to bind detectable amounts of ddAb (Fig. 5) even under conditions where several hundred thousand drug molecules remain attached to each platelet is also consistent with this concept. The finding that platelets coated with $\mathrm{ddAb}$ in the presence of tritiated quinine and then washed repeatedly retain significantly greater amounts of drug than platelets exposed to the drug in normal serum (Fig. 6), suggests the possibility that each molecule of ddAb promotes retention of several drug molecules on the platelet surface, perhaps where its $\mathrm{Fab}$ termini, occupied by drug, bind to the putative platelet receptor. An alternative explanation for DAP formation not altogether ruled out by the available data is that drug binds first to a site on the platelet to form an unstable neoantigen that is stabilized by the attachment of antibody. Additional studies are needed to distinguish between this possibility and binding via the innocent bystander mechanism.

In vivo correlates. In a series of in vivo studies, Shulman (35) showed in a patient with a potent quinidine-dependent antibody that platelet destruction sufficient to reduce platelet levels from 300,000 to $77,000 / \mu \mathrm{l}$ occurred at a plasma concentration of drug that did not exceed $4 \times 10^{-8} \mathrm{M}$. In a second patient with a weaker antibody, infusion of a much larger amount of quinidine resulted only in a slight reduction of platelets to $\sim 200,000 / \mu$ l. Quinine and quinidine are rapidly adsorbed from the gastrointestinal tract and plasma levels of patients on conventional therapy reach $20(31)$ and $14 \mu \mathrm{M}(29,30)$, respectively. If one assumes that antibody levels in our four patients at the onset of thrombocytopenia were approximately the same as when samples were obtained for study a few days later, the number of IgG molecules bound to platelets in vivo at $20 \mu \mathrm{M}$ drug and at a circulating platelet concentration of 300,000 (I.L., R.S., D.D.) and 150,000 (M.S.)/ $\mu$ l can be estimated from Fig. 1: I.L., 28,000; R.S., 46,000; D.D., 61,000; and M.S., 31,000. These quantities of platelets would adsorb $10-35 \%$ of the antibody in the four patients studied. After the initial destruction of platelets and reduction in platelet levels, even greater numbers of IgG molecules might bind to the remaining platelets, accelerating the rate of platelet clearance. On the basis of a single study, Shulman suggested that as few as 400 quinidine-dependent antibody molecules might suffice to induce platelet destruction (4). Using serum from patient I.L., we found that 5,000 IgG molecules became bound to normal platelets at a quinine level of $2.7 \times 10^{-8} \mathrm{M}$, a figure well below the therapeutic range. The relatively large number of quinine- and quinidine-induced ddA $b$ molecules that become bound to platelets under con- ditions likely to exist in vivo in a sensitized patient who ingests these drugs may explain the dramatic, sometimes catastrophic, bleeding symptoms manifested by such patients.

In view of the heterogeneity in binding affinity, level of drug required to promote binding, and the number of antibody binding sites per platelet displayed by the antibodies we studied, it seems permissable to speculate that patients who develop profound thrombocytopenia with hemorrhagic symptoms upon taking quinine or quinidine may constitute a minority of a much larger group of sensitized patients whose drug-induced antibodies either have a low $K_{\mathrm{a}}$ or bind to platelets well only at very high drug concentrations. Further studies to test these possibilities seem warranted.

\section{ACKNOWLEDGMENTS}

We thank Dr. Thomas Kunicki for his many helpful discussions throughout the course of this work and Dr. Robert Montgomery for his assistance in obtaining severe von Willebrand's platelets and for performing the Factor VIII-related antigen measurements. We also thank Kathleen Reed for her excellent technical assistance and the word processing department for the typing of this manuscript.

This work was supported by National Heart, Lung, and Blood Institute grant HL-13629 and Fellowship HL06255-01.

\section{REFERENCES}

1. Aster, R. H. 1977. Thrombocytopenia due to enhanced platelet destruction. In Hematology. W. J. Williams, E. Beutler, A. J. Erslev, and R. W. Rundles, editors. McGraw-Hill, Inc., New York. 2nd edition. 1326-1359.

2. Ackroyd, J. F. 1953. Allergic purpura, including purpura due to foods, drugs and infections. Am. J. Med. 14: 605632.

3. Miescher, P., and R. Miescher. 1952. Die Sedormid-Anaphlaxie. Schweiz. Med. Wochenschr. 82: 1279-1282.

4. Shulman, N. R. 1963. Mechanism of blood cell damage by absorption of antigen-antibody complex. In Immunopathology, Third International Symposium. P. Grabar and P. A. Miescher, editors. Schwabe and Co., Basel. 338-352.

5. Croft, J. D., Jr., and R. I. Weed. 1968. Coombs'-test positive induced by drugs: mechanisms of immunologic reactions, and red cell destruction. Ann. Intern. Med. 68: 176-187.

6. Shulman, N. R. 1958. Immunoreactions involving platelets. I. A steric and kinetic model for formation of a complex from a human antibody, quinidine as a haptene, and platelets; and for fixation of complement by the complex. J. Exp. Med. 107: 665-690.

7. Hosseinzadeh, P. K., B. G. Firkin, and S. L. Pfueller. 1980. Study of the factors that cause specific transformation in cultures of lymphocytes from patients with quinine- and quinidine-induced immune thrombocytopenia. J. Clin. Invest. 66: 638-645.

8. Pfueller, S. L., P. K. Hosseinzadeh, and B. G. Firkin. 1981. Quinine- and quinidine-dependent antiplatelet antibodies. Requirement of Factor VIII-related antigen for platelet damage and for in vitro transformation of 
lymphocytes from patients with drug-induced thrombocytopenia. J. Clin. Invest. 67: 907-910.

9. Petz, L. D., and H. H. Fudenberg. 1975. Immunologic mechanisms in drug-induced cytopenia. Prog. Hematol. 9: 185-206.

10. Petz, L. D. 1980. Drug-induced immune haemolytic anaemia. Clin. Haematol. 9: 455-482.

11. Young, G. A. R., and P. C. Vincent. 1980. Drug-induced agranulocytosis. Clin. Haematol. 9: 483-504.

12. Aster, R. H., and S. E. Enright. 1969. A platelet and granulocyte membrane defect in paroxysmal nocturnal hemoglobinuria. Usefulness for the detection of platelet antibodies. J. Clin. Invest. 48: 1190-1210.

13. Lalezari, P., and S. C. Pryce. 1980. Detection of neutrophil and platelet antibodies in immunologically-induced neutropenia and thrombocytopenia. In Manual of Clinical Immunology. N. R. Rose and H. Friedman, editors. American Society for Microbiology, Washington. 2nd edition. 744-748.

14. Lizak, G. E., and F. C. Grumet. 1979. Storage of reagent platelets for antiplatelet antibody testing in the ${ }^{51} \mathrm{Cr}$ platelet lysis assay. Clin. Pathol. 32: 191-192.

15. Nurden, A. T., D. Dupuis, T. J. Kunicki, and J. P. Caen. 1981. Analysis of the glycoprotein and protein composition of Bernard-Soulier platelets by single and two-dimensional sodium dodecyl sulfate-polyacrylamide gel electrophoresis. J. Clin. Invest. 67: 1431-1440.

16. Kunicki, T. J., M. M. Johnson, and R. H. Aster. 1978. Absence of the platelet receptor for drug-dependent antibodies in the Bernard-Soulier syndrome. J. Clin. Invest. 62: 716-719.

17. Markwell, M. A. K., S. M. Haas, L. L. Bieber, and N. E. Tolbert. 1978. A modification of the Lowry procedure to simplify protein determination in membrane and lipoprotein samples. Anal. Biochem. 87: 206-210.

18. Kunicki, T. J., and R. H. Aster. 1982. Direct quantitation of total platelet-associated IgG by electroimmunoassay. Blood. 60: 54-58.

19. Bjerrum, O. J., A. Ingild, H. Lowenstein, and B. Weeke. 1973. Carbamylated antibodies used for quantitation of human IgG. A routine method. Scand. J. Immunol. 2(Suppl. 1): 145-148.

20. Kelton, J. G., D. Meltzer, J. Moore, A. R. Giles, W. E. Wilson, J. Hirsh, P. B. Neame, P. J. Powers, I. Walker, F. Bianchi, and C. J. Carter. 1981. Drug-induced thrombocytopenia is associated with increased binding of IgG to platelets both in vivo and in vitro. Blood. 58: 524529.

21. Pfueller, S. L., L. Cosgrove, B. G. Firkin, and D. Tew. 1981. Relationship of raised platelet IgG in thrombocytopenia to total platelet protein content. $\mathrm{Br}$. J. Haematol. 49: 293-302.

22. Glode, L. M., R. R. Montgomery, C. G. Smith, and
D. B. Link. 1982. Use of monoclonal antibody to increase sensitivity and specificity in quantitative immunodiffusion assays. J. Immunol. Methods 48: 13-22.

23. Zimmerman, T. S., J. Roberts, and T. S. Edgington. 1975. Factor VIII-related antigen: multiple molecular forms in human plasma. Proc. Natl. Acad. Sci. USA. 72: 51215125.

24. Uskokovic, M. R., and J. Gutszwiller. 1973. Reinvestigation of the classical synthesis of cinchona alkaloids. II. The synthesis of quinine and its naturally occurring diastereomers from quinotoxine. Helv. Chim. Acta. 56: 1494-1503.

25. Sugiura, K., M. Steiner, and M. Baldini. 1981. Physiological effects of nonimmune platelet associated immunoglobulin G. Thromb. Haemostasis. 45: 27-33.

26. Kabat, E. A. 1976. Antigenic determinants and the size of the antibody combining site: determinants of cellmediated immunity. In Structural Concepts in Immunology and Immunochemistry. Holt, Reinhart and Winston, New York. 2nd edition. 119-166.

27. Eisner, E. V., and B. C. Korbitz. 1972. Quinine-induced thrombocytopenic purpura due to an IgM and an IgG antibody. Transfusion (Phila.). 12: 317-321.

28. Kekomaki, R., A. Rajamaki, and G. Myllyla. 1980. Detection of quinidine-specific antibodies with platelet ${ }^{125} \mathrm{I}$ labeled staphylococcal protein A test. Vox Sang. 38: 1218.

29. Kessler, K. M., D. T. Lowenthal, H. Warner, T. Gibson, W. Briggs, and M. M. Reidenberg. 1974. Quinidine elimination in patients with congestive heart failure or poor renal function. N. Engl. J. Med. 290: 706-709.

30. Hirschfeld, D. S., C. T. Ueda, M. Rowland, and M. M. Scheinman. 1977. Clinical and electrophysiological effects of intravenous quinidine in man. Br. Heart J. 39: 309-316.

31. Rollo, I. M. 1980. Drugs used in the chemotherapy of malaria. In The Pharmacological Basis of Therapeutics. L. S. Goodman and A. Gilman, editors. MacMillan Publishing Co., Inc., New York. 1038-1060.

32. Hosseinzadeh, P., S. Pfueller, and B. G. Firkin. 1981. The recognition of two platelet antigens by quinine/ quinidine antibodies. Clin. Res. 29: 335A.

33. Shulman, N. R. 1972. Immunologic reactions to drugs. N. Engl. J. Med. 287: 408-409.

34. Hill, T. L. 1958. Immunoreactions involving platelets. II. Theoretical analysis of the model. J. Exp. Med. 107: 691-695.

35. Shulman, N. R. 1958. Immunoreactions involving platelets. IV. Studies on the pathogenesis of thrombocytopenia in drug purpura using test doses of quinidine in sensitized individuals. Their implications in idiopathic thrombocytopenia purpura. J. Exp. Med. 107: 711-729. 